\title{
E-Learning Enrichment to Become an Effective Knowledge Management Tool
}

\author{
Maryam Khademi, Hoda Kabir, and Maryam Haghshenas
}

\begin{abstract}
Knowledge management and e-Learning both address the same fundamental problem which is to facilitate learning in organizations. But they approach the problem with two different paradigms, resulting in to two different types of systems. In this paper we investigate on relations between e-Learning and Knowledge Management technology and then illustrate some suggestions to enhance the capture, organization and delivery of large amounts of knowledge by improving and enriching e-Learning contents.
\end{abstract}

Index Terms-E-Learning, Intelligent Content, Knowledge Management, Metadata, Motivation, Organizational Learning.

\section{INTRODUCTION}

One of the difficulties facing organizations and researchers alike is that knowledge management, while being intuitively important, is intellectually elusive. It is important because, "with rare exceptions, the productivity of a modern corporation or nation lies more in its intellectual and system capabilities than in its hard assets..." [1]. It is elusive because, "to define knowledge in a non-abstract and non-sweeping way seems to be very difficult and Knowledge easily becomes everything and nothing" [2]. On the other hand fundamental to today's knowledge economy is how companies foster learning and obtain and retain knowledge from their workers. The rapid pace of change in what workers need to know, the growth of the internet, and accelerated global competition, all contribute to the requirement that successful companies efficiently harvest and use knowledge [3].

Firms have embraced the notion of "Knowledge" as an asset that creates value when shared. Training is no longer seen as an extravagance after a good year of profits, but as a necessity in order to keep up with competitors. Equally these days, companies worry less about training workers and then having them leave and more about not training workers and having them stay. This makes the corporate training knowledge management market the most promising for e-Learning. In business, network technology makes e-Learning possible and allows it to take place during the course of work. Corporations are already heavily wired and conduct an increasing volume of their business, both internally and externally, over the internet. The speed at

Manuscript received October 15, 2011; revised October 31, 2011.

M. Khademi is with Islamic Azad University, Tehran south branch, Iran (e-mail: khademi@azad.ac.ir).

H. Kabir is with Shahid Beheshti university, Tehran, Iran (e-mail: h.kabir@mail.sbu.ac.ir).

M. Haghshenas is with The Information Technology Management Association, Islamic Azad University, Science \&Research Branch, Tehran, Iran (e-mail: m.haghshenas@srbiau.ac.ir). which this makes it possible to introduce new products, services, and features means that employees have to learn and consolidate new information more and more rapidly. Educating these workers in an efficient and effective way becomes critical to the knowledge management of a firm since organizational survival depends on the service provided to customers and much of this service requires up-to-date knowledge of new products and their ever changing features.

Knowledge management is a discipline originating from management studies, but always going hand in hand with information technologies both as a reason for its necessity and as a technical solution for the implementation. Knowledge management takes an organizational perspective on learning, and the main problem it tries to address is the lack of sharing knowledge among members of the organization. Its solutions try to enable and encourage the individuals' making explicit their knowledge by creating knowledge assets or engaging in discussions.

In this paper, we will describe the connection between e-Learning and knowledge management and some recommends are suggested to improve the produced content for being used as a knowledge management tool. Section 2 is comprised of main concepts about knowledge management $(\mathrm{KM})$ and organizational learning (OL). E-Learning construction and its advantages are presented in section 3. In section 4, the relationship between e-Learning and knowledge management is defined. Section 5, will propose some ways to enhance our e-Learning content for KM aims and section 6, will specify motivational Factors in e-Learning. Finally, the paper will be ended by conclusion.

\section{KNOWLEDGE MANAGEMENT AND ORGANIZATIONAL LEARNING}

A For centuries, scientists, philosophers and intelligent laymen have been concerned about creating, acquiring, and communicating knowledge and improving the re-utilization of knowledge. However, it is only in the last 15-20 years or so that a distinct field called "knowledge management" has emerged.

Knowledge is often defined as a "justified personal belief". There is much taxonomy that specifies various kinds of knowledge. The most fundamental distinction is between "tacit" and "explicit" knowledge. Tacit knowledge inhabits the minds of people and is either impossible, or difficult, to articulate. Most knowledge is initially tacit in nature; it is laboriously developed over a long period of time through trial and error, and it is underutilized because the organization does not know what it knows. Some knowledge is embedded in business processes, activities, and relationships that have 
been created over time through the implementation of a continuing series of improvements. On the other hand, explicit knowledge exists in the form of words, sentences, documents, organized data, and computer programs and other different forms. If one accepts the useful "difficult-to-articulate" concept of tacit knowledge, a fundamental problem of KM is to explicate tacit knowledge and then to make it available for use by others.

Knowledge Management is based on the premise that, just as human beings which are unable to draw on the full potential of their brains, organizations are generally not able to fully utilize the knowledge that they possess. Knowledge management is the planning, organizing, motivating, and controlling of people, processes and systems in the organization to ensure that its knowledge-related assets are improved and effectively employed. Knowledge-related assets include knowledge in the form of printed documents such as patents and manuals, knowledge stored in electronic repositories such as a "best-practices" database, employees' knowledge about the best way to do their jobs, knowledge that is held by teams who have been working on focused problems and knowledge that is embedded in the organization's products, processes and relationships. Through KM, organizations seek to acquire or create potentially useful knowledge and to make it available to those who can use it at a time and place that is appropriate for them to achieve maximum effective usage in order to positively influence organizational performance. It is generally believed that if an organization can increase its effective knowledge utilization by only a small percentage, great benefits will result [4].

Most organizations focus primarily on one or the other of two broadly defined KM strategies "codification" or "personalization". Codification is primarily implemented in the form of electronic document systems that codify and store knowledge and permit its easy dissemination and reuse. This strategy is based on "re-use economics" which means to invest once in creating and acquiring a knowledge asset and reuse it many times. Personalization, on the other hand, focuses on developing networks to facilitate people-to-people knowledge transfer and sharing. It is based on "expert economics" which means channelling individual expertise to others with less expertise that may employ it to further the organization's goals.

The processes of KM involve knowledge acquisition, creation, refinement, storage, transfer, sharing, and utilization. The KM function in the organization operates these processes, develops methodologies and systems to support them, and motivates people to participate in them. The goals of KM are the leveraging and improvement of the organization's knowledge assets to effectuate better knowledge practices, improved organizational behaviors, better decisions and improved organizational performance.

Although individuals certainly can personally perform each of the KM processes, KM is largely an organizational activity that focuses on what managers can do to enable KM's goals to be achieved, how they can motivate individuals to participate in achieving them and how they can create social processes that will facilitate KM success.

The relationship between knowledge management and organizational learning is conceptualized in various ways. One of the most important considerations in this area is to view OL as the goal of KM. By motivating the creation, dissemination and application of knowledge, KM initiatives pay off by helping the organization embed knowledge into organizational processes so that it can continuously improve its practices and behaviors and pursue the achievement of its goals.

$\mathrm{KM}$ in an Organization is shown in Fig. 1. KM processes directly improve organizational processes, such as innovation, collaborative decision-making, and individual and collective learning. These improved organizational processes produce intermediate outcomes such as better decisions, organizational behaviors, products, services and relationships. These, in turn, lead to improved organizational performance [4], [5].

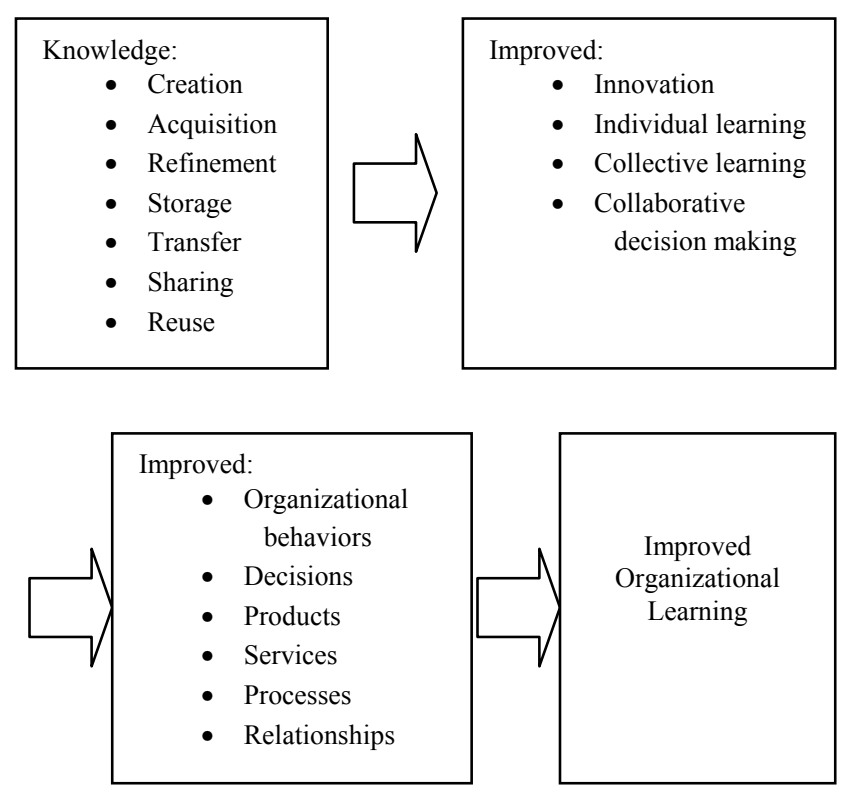

Fig. 1. KM in an Organization

\section{E-LEARNING AND THE BENEFITS}

E-Learning, or better to call computer supported learning, focuses on the individual's acquisition (or rather construction) of new knowledge and the technological means to support this construction process. One of the main assumptions in e-Learning coming from pedagogy is that learning needs or can be improved through guidance. The typical form of guidance is the teacher or tutor organizing the learning process. But e-Learning has also transferred the concept of lessons to computer-based courses, consisting of several learning resources that are connected with one another in a meaningful way. This comes from the pedagogical insight that it matters for the efficiency of learning in which order learning resources are offered, which can encompass more traditional courses, modular learning objects, and also more elusive interaction possibilities. This concept of guidance also leads to an asymmetry and a separation of the roles author/tutor and learner. Authors and tutors are pedagogically and didactically trained persons while learners 
typically are not [6], [7].

E-Learning is beneficial to education, corporations and to all types of learners. It is affordable, saves time, and produces measurable results. Some other advantages of e-Learning we can mention are:

- Cost effective: E-Learning is more cost effective than traditional learning because less time and money is spent traveling. Since e-Learning can be done in any geographic location and there are no travel expenses, this type of learning is much less costly than doing learning at a traditional institute.

- Flexibility: Flexibility is a major benefit of e-Learning. e-Learning has the advantage of taking class anytime anywhere. Education is available when and where it is needed. E-Learning can be done at the university, at the office, at home, on the road, 24 hours a day, and seven days a week. Learners like e-Learning because it accommodates different types of learning styles. They have the advantage of learning at their own pace. Students can also learn through a variety of activities that apply to many different learning styles. Learners can fit e-Learning into their busy schedule. If they hold a job, they can participate in e-Learning right at their desk.

- Personalized learning: E-Learning encourages students to peruse through information by using hyperlinks and sites on the worldwide Web. Learners are able to find information relevant to their personal situations and interest. E-Learning allows selection of learning materials that meet their level of knowledge, interest and what they need to know to perform more effectively in an activity. E-Learning is more focused on the learner and it is more interesting for the learner because it is information that they want to learn. E-Learning is flexible and can be customized to meet the individual needs of the learners [8].

- Develops knowledge: E-Learning helps develop knowledge of the Internet. This knowledge will help learners throughout their careers. E-Learning encourages learners to take personal responsibility for their own learning. When they succeed, it builds self-knowledge and self-confidence [9].

\section{RELATIONSHIP BETWEEN KNOWLEDGE MANAGEMENT AND E-LEARNING}

$\mathrm{KM}$ and e-Learning both address the same fundamental problem: facilitating learning in organizations. The similarities of knowledge management processes to e-Learning processes make the two easy partners for companies that have recognized their importance. Properly developed, e-Learning creates a growing repository of knowledge that will continuously deliver to employees just what they need to know at any particular moment, and in a style that each individual can understand. e-Learning at this level is similar to its efficiency counterpart in inventory management; it can be thought of as "just in time learning". In short, e-Learning permits participants to acquire knowledge, pass it from one person to another, apply it to organizational problems/opportunities, and store that knowledge for future use. If this sounds familiar it is because, essentially, knowledge management and e-Learning are both about knowledge generation (acquisition, creation, capture, and adoption), knowledge storage, knowledge distribution, and knowledge application [10].

E-Learning potential benefits to business are numerous. Companies are seeking the kind of easy accessible, highly flexible training that e-Learning can deliver in order to contend with the rapid pace of change in business and shorter product cycles. One of the most obvious benefits to e-Learning is the economic advantage from not having to fly employees to attend expensive seminars and thus lose important work time. In addition, e-Learning personalizes the learning experience and allows for greater flexibility. Employees can take courses around their schedules and at their own pace while maintaining a consistency of material with their fellow workers. Through online training, companies increase the likelihood of getting training to employees wherever they live or work and, as a result, retain valuable employees longer [11], [12].

\section{ENRICHING E-LEARNING CONTENTS to BECOME AN EFFECTIVE KM TOOL}

Several trends are spurring the momentum behind e-Learning. One, as stated earlier, is the need for firms to keep up with the ever changing businesses environment and shorter product lifecycles. Another trend is the growing importance of information sharing. e-Learning can be taken outside of company firewalls and can be used to educate firm partners, customers, and suppliers, in addition to the firm's employees. In return, the firm can generate new knowledge through the use of chat rooms, surveys, etc.

The e-Learning content can get improved to end in a better resource for learning in organizations. In this way if the content becomes structurally rich, and semantically aware, and therefore discoverable, reusable, reconfigurable and adaptable the result will be an intelligent content. Intelligent content is the one which is limited only by our imaginations. By the use of this content we can automatically deliver knowledge to multiple channels, personalize content, and enable employees to easily find the information and knowledge they need no matter how complex their requirements are, deepen user's relationships, share content across organizational silos, manage content throughout its lifecycle, and rapidly adapt information to changing needs, and so on [13], [14].

By the way, to enrich e-Learning content is to employ metadata. Metadata is structured information that describes, explains, locates, or otherwise makes it easier to retrieve, use, or manage an information resource. An important reason for creating descriptive metadata is to facilitate discovery of relevant information. In addition to resource discovery, metadata can help organize electronic resources, facilitate interoperability and legacy resource integration, and provide digital identification, and support archiving and preservation. Some classify the representation of metadata in e-Learning applications into three categories: standard metadata, semi-semantic metadata, and semantic metadata but the trend nowadays is to use semantic metadata for its flexibility, extensibility, and reasoning which leads to pleasing results in facilitating large scale collaboration [15]. 


\section{MOTIVATION FACTORS FOR E-LEARNING EDUCATORS IN ORGANIZATIONS}

E-Learning has the potential to open up a number of different opportunities for vast numbers of learners across the organization. Without the proper motivation for learners to engage in the learning experience, however, these e-Learning initiatives will be unsuccessful. As Wlodkowski states, "Motivation is not only important because it is a necessary casual factor of learning, but because it mediates learning and is a consequence of learning as well" [16].

For a long time, motivation has been seen in e-learning as a matter of design. In other words, proper instructional design and provision of suitable learning activities would guarantee to engage all learners. However, many educators and institutions are beginning to realize that there is more to motivation than meets the eyes. It is not always the case that if the instruction is of good quality then motivation will follow. In this case there are some theories and models for increasing motivation in e-Learning. Some of the most important one's are Keller's ARCS, Wlodkowski's Time Continuum, and Moshinskies's model and Social Cognitive Learning theory.

The ARCS model is named after its four main factors: Attention, Relevance, Confidence and satisfaction. Attention involves engaging the learner by the use of interesting graphics, animation or any kind of event that introduces incongruity or conflict. Relevance includes providing consistent goals that are connected to the learners' past experiences and future goals and are compatible with their individual learning styles. Confidence means helping students to establish positive expectancies for success and has links to the self efficiency and Attribution theory. Finally, satisfaction contains designing instruction so that learners gain positive feelings about their learning experiences [17].

Wlodkowski's time continuum model of motivation draws on approaches from linguistics, cognitive psychology, and motivation research. While it has many similarities to the ARCS model, it focuses more on the role motivation plays in different stages of the learning process. It divides the learning process up into three critical stages: the beginning of the learning process, during the learning process, and the end of the learning process. The beginning of the learning process should focus on attitudes and needs. During the learning process, emphasis should be placed on stimulation and effect and the end of the learning experience should focus on competence and reinforcement [18].

A more recent motivational model that has gained some recognition is Moshinskie's model. Moshinskie argues that there are two types of learners; those with active attitudes towards life (those with intrinsic motivation and need very little extrinsic motivation) and those with a passive attitude towards life (those who lack intrinsic motivation and need more extrinsic motivation). He provides a model, like Wlodkowskie, which intends to improve learner's motivation before, during, and after online courses. This model tries to create and explain extrinsic motivational techniques that might complement the intrinsic needs of learners [19].

Social cognitive learning theory emphasizes the importance of self-efficacy and self-regulation in e-Learning.
Self-efficacy refers to a person's belief about his or her capacity to perform a certain task at a certain level, while self-regulation refers to the control of the learning activity [20].

\section{CONCLUSION}

In this paper, we presented some recommendations to make e-Learning content enhanced for knowledge management objectives and to motivate educators to participate more in the organizational courses. The importance of e-Learning may be summarized as this: it incorporates the traditional pedagogy of education with the advantages of technology to capture, disseminate and share knowledge throughout an organization. Besides, knowledge management is considered to be an important, and arguably necessity, tenet of modern day business strategy. The "intermediate outcomes" of KM are improved organizational behaviors, decisions, products, services, processes and relationships that enable the organization to improve its overall performance.

\section{REFERENCES}

[1] J. B. Quinn, P. Anderson, and S. Finkelstein, "Leveraging intellect," Academy of Management Executive, vol. 10, no. 3, 1996.

[2] M. Alvesson and H. Willmott, 1996, Making Sense of Management, Sage, London.

[3] W. R. King, " Knowledge Management and Organizational Learning," Knowledge management and organizational learning, Annals of information systems. University of Pittsburg, 2009, pp. 3-11.

[4] R. Cross, and L. Baird, "Technology I not enough: Improving performance by building organizational memory," Sloan Management Review, vol.41, no.3, pp.69-79, 2000.

[5] W. R. King, "Communications and information processing as a critical success factor in the effective knowledge organization," International Journal of Business Information Systems, vol.10, no.5, pp. 31-52, 2005.

[6] Viorina-Maria Judeu, Emma-Margareta Valeanu. e-Learning using the Basic Knowledge Management Process in the Organizational Growth. Int. J. of Computers, Communications \& Control, Proc. ICCCC., pp. 349-352, 2008.

[7] M. Alavi and D. E. Leidner, "Review: knowledge management and knowledge management systems: conceptual foundations and research issues", MIS Quarterly, vol.25, no.1, 2001.

[8] S. Hicks, "Evaluating e-Learning", Training and Development, December, vol.54, no. 12 .

[9] H. Keynejad, M. Khademi, H. Kabir, M. Haghshenas. e-Learning Content Authoring Tools and Introducing a Standard Content Constructor Engine, 2nd International Symposium on Computing in Science \& Engineering / June 1-4, 2011 / kusadasi-Turkey.

[10] Darrell Woelk, and Shailesh Agarwal. Integration of e-Learning and Knowledge Management. 2002.

[11] Rosemary H. Wild, and Kenneth A. Griggs, and Tanya Downing. A Framework for e-Learning as a tool for knowledge management, Industrial Management \& Data System, vol.102, no.7, pp. 371-380, 2002.

[12] J. F. Sowa, knowledge representation: logical, philosophical and computational foundations, Brooks Cole Publishing Co., 2000.

[13] Yan Peng. Intelligent Content Push for SCORM-based e-Learning systems. International Symposium on Intelligent Information Technology Application Workshops, 2008. IITAW.

[14] Weihong Huang, David Webster, Dawn Wood and Tanko Ishaya. An intelligent semantic e-Learning framework using context-aware semantic web technologies, vol. 37, no.3. pp. 351-373, 2006.

[15] S. Arun, Metadata management: past, present and future. Decision Support Systems, vol.37, no.1, pp. 151, 2004.

[16] R. J. Wlodkowskie, (1985). Enhancing adult motivation to learn. San Francisco: Jossey-Bass, P.4. 
[17] J. M. Keller, \& K. Suzuki,. Learner motivation and e-learning design: a multinational validated process. Journal of Educational Media, vol.29, no.3, pp 232, 2004.

[18] C. Hodges, "Designing to motivate: Motivational techniques to incorporate in e-learning experiences," The Journal of Interactive Online Learning, vol.2, no.3, pp. 3-4, 2004.

[19] J. Moshinskie, "How to keep e-learners from e-scraping," Performance improvement, vol.40, no.6, 2001

[20] M. Cocea, \& S. Weibelzahl, (n.d.). Motivation-included or excluded from e-learning, p. 2-3. Retrieved on June 24, 2008 from http://www.easy-hub.org/stephan/cocea-selda06.pdf

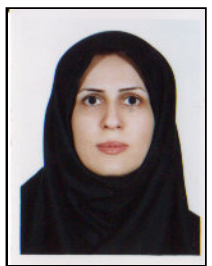

Maryam Khademi is born in Boroujerd on 1967 and she received B.Sc. in Pure Mathematics from Tarbiat Moaalem University, Tehran, Iran in 1989, M.Sc. in Pure Mathematics from Islamic Azad University North Tehran Branch, Iran in 1991, M.Sc. in Applied Mathematics from Iran University of Science and Technology, Tehran, Iran in 1993, and Ph.D. degree in applied mathematics from University of Tehran in 2004 She has various publications in different fields and he $\mathrm{CV}$ is located on link: http://old.azad.ac.ir/faculty/khademi89.htm. She is interested in finite groups Theory, Graph Theory, Computer Science and Artificial Intelligence.

Dr. Khademi is the faculty member of Islamic Azad University, Tehran south branch.

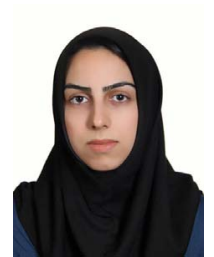

Hoda Kabir is born in London on 1985 and has earned a B.Sc. degree in Computer Software Engineering from Islamic Azad University, south Tehran branch on 2010 and is M.Sc. degree student in IT engineering at Shahid Beheshti University. She is interested in producing e-Learning content, Enterprise Architecure \& Multimedia fields.

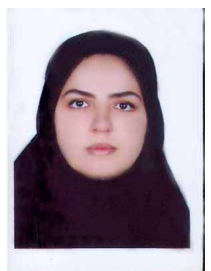

Maryam Haghshenas is born in Bijar on 1985 and has earned B.Sc. degree in Computer Hardware engineering from Islamic Azad University, South Tehran branch, Tehran, Iran in 2007. then she received M.Sc. degree in IT management at Islamic Azad University, Science \& Research branch, Tehran, Iran in 2011. She was Network Technician in Pars company on 2007 then project manager of Information Technology systems Department in Gilas computer company on 2010, Activity fields of gilas company is to be the preferred information security partner for organizations, and to deliver products and services to the customer, implementation of projects about Security of Network and Design ISMS-ITSM-BCMS-SSE/CMM with standards included (ISO 27001, 20000, 25999, 21827). She has published "Information technology security \& service management system" in Information Society of Iran journal on July 2010, and the other publication in different fields .She is interested in construction of content in e-Learning \& Indexing on components of multimedia, categories of authoring tools and IT Systems management.

Ms. Haghshenas is a member of Young Researchers Club at Islamic Azad University-Tehran south branch, Student Researchers Club in Iran, Islamic Azad University Graduations Association and also a member of the Information Technology Management Association at Islamic Azad University, Science \&Research Branch in Iran. 